Abdelraouf A. Elmanama ${ }^{1 *}$, Mariam R.

\section{Antifungal susceptibility pattern of Candida spp. isolated from vaginal discharge of pregnant women}

Al-Reefi; Lina Al Najjar; Sojoud S. Abu Eita; Basma R. Al Hag Ahmad.

1 Department of Medical Laboratory Sciences Faculty of Health Sciences Islamic University of Gaza, Gaza Strip, Palestine

\section{Corresponding author*}

e-mail address: elmanama_144@yahoo.com

https://doi.org/10.33976/IUGNS.28.1/2020/07

\begin{abstract}
:
Vaginal candidiasis is common fungal infections among pregnant women. The aim of this study is to determine antifungal susceptibility pattern of Candida spp. isolated from vaginal discharge and to investigate possible risk factors associated with Candida infection. One hundred high vaginal swabs were collected from pregnant women complaining from abnormal discharge from various clinics in Gaza city, during 2019. Samples were plated on Sabouraud Dextrose Agar supplemented with chloramphenicol. Candida isolates were identified to the Genus level based on cultural and morphological characteristic. The susceptibility to seven antifungals was determined using disc diffusion method. Demographic, environmental, behavioral and other possible risks factors associated with vaginal candidiasis were recorded through an interview with patients before collecting the vaginal swabs and after obtaining a verbal consent. Data analysis was done using the SPSS software. Candida spp. was isolated from $43 \%$ of vaginal swabs of pregnant women with discharge. Variations existed in the susceptibilities of the different Candida isolates to antifungals. Amphotericin B the most effective with $0 \%$ resistance followed by itraconzaol and nystatin with $9.4 \%$ resistance. Resistance to miconazole, ketoconazole, voriconazole and fluconazole was $11.6 \%$. Statistically significant symptoms associated with positive Candida spp. cultures among pregnant women included; redness of vaginal area, secretions, yeast-like smell, urinary urgency, low sexual desire, itching and irritation $(\mathrm{p} \leq 0.05)$. No statistical significance difference with regard to burning urinary sensation and painful intercourse. Candida spp. was isolated from $43 \%$ of vaginal swabs from pregnant women. Risks factors should be minimized by patient education and routine testing of pregnant women.
\end{abstract}

\section{Keywords:}

Antifungal resistance

Candidiasis, Gaza, Palestine, Pregnant women, Vaginal Discharge. 


\section{Introduction:}

Candida species are ubiquitous, ranging from free saprophytes through endo-symbionts of animals, to pathogens in many animals and in humans. Some of the pathogenic species are of medical importance, especially Candida albicans. However, the prevalence of other non-albicans Candida species as human pathogens is on the rise worldwide (1).

Vulvovaginal candidiasis (VVC) is considered as the second most common cause of vaginal infections, after bacterial vaginosis that is reported at gynaecological clinics (2). An estimated cost of diagnosis and treatment of VVC which take into consideration, loss of productivity and absenteeism in the U.S. is about $\$ 1$ billion yearly (2). Candida albicans is the most frequent causative agent in about $80-90 \%$ of VVC infections even though other non albicans Candida species are increasingly reported (2).

VVC is the most common gynecological ruling among women of child-bearing age (3). Among sexually active women, $75 \%$ have at least once experienced symptomatic VVC, which usually presents as soreness, burning, itching and abnormal curd-like vaginal discharge $(4,5)$. Pregnancy was the commonest factor $(55 \%)$ followed by usage of broad-spectrum antibiotics $(8 \%)(6)$.

Recommendations for vulvovaginitis diagnosis included speculum examination, and microscopic examination of slide from vaginal exudates to look for protozoan (Trichomonas vaginalis), bacterial (Gardnerella vaginalis) or fungal (Candida spp.) agents, followed by vaginal fluid specimen culture to confirm the diagnosis. Otherwise, the confirmatory diagnosis based on culture is not routinely performed nor generally advised in many regions, because all procedures are expensive and time consuming (7).

Many reports from around the world reports increasing frequency of Candida resistance to common antifungals. The main objective of this study is to determine the prevalence of vaginal candidiasis among pregnant women with abnormal discharge and their resistance profile to antifungals.

\section{Methods}

\subsection{Sample collection and culture}

A total of 100 high vaginal swab samples were collected from symptomatic and asymptomatic pregnant women aging between (18-49) years attending ante-natal clinics during the period from December 2018 to June 2019. Samples were transport to the Microbiology laboratory at the Islamic University of Gaza within 2 hours and were inoculated onto the

surface of Sabouraud Dextrose Agar (SDA) with chloramphenicol, then incubation on $37{ }^{\circ} \mathrm{C}$ for 48 hours.

\subsection{Antifungal susceptibility testing}

Antifungal susceptibility testing was undertaken by the disk diffusion method. Fluconazole disk (10 $\mu \mathrm{g})$, itraconazole $(10 \mu \mathrm{g})$, voriconazole $\left(\begin{array}{ll}10 & \mu \mathrm{g}\end{array}\right)$, amphotericin B (10 $\mu \mathrm{g})$, nystatin (100 IU), and Ketokonazole antifungal discs were applied on MHA as recommended by the Clinical Laboratory Standard Institute (CLSI). The plates were incubated in ambient air at $35^{\circ} \mathrm{C}$ and read after 24 hours. Interpretation of all antifungal susceptibility (susceptible $\mathrm{S}$, intermediate I and resistant R) was done according to CLSI standards (8).

\section{Results.}

The study sample comprised of swabs from 100 pregnant woman attending Gaza clinics, aged between 18-49 years (Table 1 ).

Table 1: Distribution of study subjects according age group location, and residency, $(n=100)$

\begin{tabular}{|l|c|c|}
\hline Variable & Category & \% \\
\hline \multirow{3}{*}{ Age } & $18-28$ & 69 \\
\cline { 2 - 3 } & $29-38$ & 25 \\
\cline { 2 - 3 } & $\geq 39$ & 6 \\
\hline \multirow{3}{*}{ Governorate } & Gaza & 63 \\
\cline { 2 - 3 } & Middle and South & 8 \\
\cline { 2 - 3 } & North Gaza & 29 \\
\hline \multirow{2}{*}{ Residence } & City & 75 \\
\cline { 2 - 3 } & Camp & 25 \\
\hline
\end{tabular}

Culturing results indicated that $43 / 100$ of the pregnant woman were positive for Candida spp. with an overall prevalence $43 \%$. As shown in table (2) the highest 
vaginal Candida positive cultures was among the 18-28 age group with a prevalence of $46.4 \%$, but no significant difference among different age groups (P value $=0.1$ ). Residence and the number of rooms in the house showed statistically significant difference (P value $=0.02$ and 0.03 respectively).

Table 2: Distribution of Candida positive culture distributed by age, income, residence and room number

\begin{tabular}{|c|c|c|c|c|}
\hline \multicolumn{2}{|c|}{ Risk factors } & $\begin{array}{c}\text { Positive } \\
\text { N (\%) }\end{array}$ & $\begin{array}{c}\text { Negative } \\
\text { N (\%) }\end{array}$ & $\begin{array}{c}\text { p- } \\
\text { value }\end{array}$ \\
\hline \multirow{3}{*}{ Age } & $18-28$ & $32(46.4)$ & $37(53.6)$ & \multirow{3}{*}{0.13} \\
\hline & $29-38$ & 7 (28.0) & $18(72.0)$ & \\
\hline & $\geq 39$ & $4(66.7)$ & $2(33.3)$ & \\
\hline \multirow{3}{*}{ Income } & $<1000$ & $20(37.7)$ & $33(62.3)$ & \multirow{3}{*}{0.1} \\
\hline & $\begin{array}{l}1000- \\
1600\end{array}$ & $14(41.2)$ & $20(58.8)$ & \\
\hline & $\geq 1700$ & $9(69.2)$ & $4(30.8)$ & \\
\hline \multirow[t]{2}{*}{ Residency } & City & $37(49.3)$ & $38(50.7)$ & \multirow{2}{*}{0.02} \\
\hline & Camp & $6(24.0)$ & $19(76.0)$ & \\
\hline \multirow{5}{*}{$\begin{array}{l}\text { Room } \\
\text { number }\end{array}$} & One & $9(52.9)$ & $8(47.1)$ & \multirow{5}{*}{0.03} \\
\hline & Two & $15(44.1)$ & $19(55.9)$ & \\
\hline & Three & $8(25.8)$ & $23(74.2)$ & \\
\hline & Four & $11(68.8)$ & $5(31.3)$ & \\
\hline & $\geq 5$ & $0(0)$ & $2(100)$ & \\
\hline
\end{tabular}

The results of antifungal susceptibility testing is illustrated in table (3). No resistance was found against amphotericin B. Resistance to Ketoconazole, fluconazole, miconazole and voriconazole was $11.6 \%$, while lower resistance was found against itraconazole and nystatin which was $9.3 \%$ as shown table (3).

Table 3: Antifungal susceptibility pattern of isolated Candida spp.

\begin{tabular}{|l|c|c|c|c|}
\hline \multirow{2}{*}{ Antifungal drug } & \multicolumn{2}{|c|}{$\mathbf{R}$} & \multicolumn{2}{c|}{ S } \\
\cline { 2 - 5 } & $\mathbf{N}$ & $\mathbf{\%}$ & $\mathbf{R}$ & \% \\
\hline Ketokonazole & 5 & 11.6 & 38 & 88.4 \\
\hline Fluconazole & 5 & 11.6 & 38 & 88.4 \\
\hline Amphotericin B & 0 & 0.0 & 43 & 100 \\
\hline Itraconazole & 4 & 9.3 & 39 & 90.7 \\
\hline Nystatin & 4 & 9.3 & 39 & 90.7 \\
\hline Miconazole & 5 & 11.6 & 20 & 88.4 \\
\hline Voriconazole & 5 & 11.6 & 38 & 88.4 \\
\hline
\end{tabular}

Prior use of antibiotics (during the last 6 months from infection) did not show significant difference $(p=0.1)$ despite the fact that higher rate of infection (51.2\%) was found among those who took antibiotics compared to only $37.3 \%$ among those who did not. Previous UTI $(p=0.4)$, taking cortisol or its derivatives $(p=0.6)$, use of contraceptives $(p=0.7)$, the number of live births $(\mathrm{P}=0.2)$, and abortion $(\mathrm{p}=0.5)$ did not show statistically significant differences. While, previous Vaginitis $(p=0.03)$, carbohydrates consumption $(p<0.01)$, sleep anxiety $(\mathrm{p}<0.01)$, general mode $(\mathrm{p}=<0.01)$, using tight underwear $(\mathrm{p}=0.01)$, and wearing tight outfit $(\mathrm{p}=$ $<0.01$ ) were find to be statistically significant risk factors. (Table 4).

Table 4: Possible risk factors associated with vulvovaginal candidiasis

\begin{tabular}{|c|c|c|c|c|}
\hline \multicolumn{2}{|c|}{ Possible Risk factors } & $\begin{array}{l}\text { Positive } \\
\text { N }(\%)\end{array}$ & $\begin{array}{l}\text { Negative } \\
\mathbf{N}(\%)\end{array}$ & p-value \\
\hline \multirow{2}{*}{$\begin{array}{l}\text { Prior antibiotic use (last } 6 \\
\text { months) }\end{array}$} & Yes & $21(51.2)$ & $20(48.8)$ & \multirow{2}{*}{0.1} \\
\hline & No & $22(37.3)$ & $37(62.7)$ & \\
\hline \multirow{2}{*}{ Previous UTI } & Yes & $24(47.1)$ & $27(52.9)$ & \multirow{2}{*}{0.4} \\
\hline & No & $19(38.8)$ & $30(61.2)$ & \\
\hline \multirow{2}{*}{ Previous Vaginitis } & Yes & $29(52.7)$ & $26(47.3)$ & \multirow{2}{*}{0.03} \\
\hline & No & $14(31.1)$ & $31(68.9)$ & \\
\hline \multirow{2}{*}{ Cortisol/derivatives } & Yes & $2(33.3)$ & $4(66.7)$ & \multirow{2}{*}{0.6} \\
\hline & No & $41(43.6)$ & $53(56.4)$ & \\
\hline \multirow{2}{*}{ Use of contraceptive } & Yes & $18(40.9)$ & $26(44.6)$ & \multirow{2}{*}{0.7} \\
\hline & No & $25(44.6)$ & $31(54.4)$ & \\
\hline \multirow{3}{*}{ Number -live- births } & None & $17(54.8)$ & $14(45.2)$ & \multirow{3}{*}{0.2} \\
\hline & $1-2$ & $15(39.5)$ & $23(60.5)$ & \\
\hline & $\geq 3$ & $11(35.5)$ & $20(64.5)$ & \\
\hline \multirow{5}{*}{ Abortion } & 0 & $33(54.8)$ & $39(54.2)$ & \multirow{5}{*}{0.5} \\
\hline & 1 & $6(35.3)$ & $11(64.7)$ & \\
\hline & 2 & $2(25)$ & $6(75.0)$ & \\
\hline & 3 & $1(50)$ & $1(50)$ & \\
\hline & 5 & $1(100)$ & $0(0.0)$ & \\
\hline
\end{tabular}




\begin{tabular}{|c|c|c|c|c|}
\hline \multicolumn{2}{|c|}{ Possible Risk factors } & $\begin{array}{c}\text { Positive } \\
\text { N }(\%)\end{array}$ & $\begin{array}{c}\text { Negative } \\
\mathbf{N}(\%)\end{array}$ & p-value \\
\hline \multirow{4}{*}{ Carbohydrates consumption } & Large & $22(95.7)$ & $1(4.3)$ & \multirow{4}{*}{0.00} \\
\hline & Moderate & $16(59.3)$ & $11(40.7)$ & \\
\hline & Small & $2(6.7)$ & $28(93.3)$ & \\
\hline & Very small & $3(15.0)$ & $17(85.0)$ & \\
\hline \multirow{2}{*}{ Number of current wives } & 1 & $43(43.4)$ & $56(56.6)$ & \multirow{2}{*}{0.3} \\
\hline & 2 & $0(0)$ & $1(100)$ & \\
\hline \multirow{2}{*}{ Husband is smoker } & Yes & $23(46.0)$ & $27(54.0)$ & \multirow{2}{*}{0.5} \\
\hline & No & $20(40)$ & $30(60)$ & \\
\hline \multirow{2}{*}{ Sleep anxiety } & Yes & $33(67.3)$ & $16(32.7)$ & \multirow{2}{*}{0.00} \\
\hline & No & $10(19.6)$ & $41(80.4)$ & \\
\hline \multirow{4}{*}{ Mode usually } & Normal & $5(31.3)$ & $11(68.8)$ & \multirow{4}{*}{0.00} \\
\hline & Stable & $5(15.2)$ & $28(84.8)$ & \\
\hline & Worried & $23(60.5)$ & $15(39.5)$ & \\
\hline & Nervous & $10(76.9)$ & $3(23.1)$ & \\
\hline \multirow{2}{*}{ Cottony underwear } & Yes & $36(43.9)$ & $46(56.1)$ & \multirow{2}{*}{0.6} \\
\hline & No & $7(38.9)$ & $11(61.1)$ & \\
\hline \multirow{2}{*}{ Tight underwear } & Yes & $33(64.7)$ & $18(35.3)$ & \multirow{2}{*}{0.00} \\
\hline & No & $10(24.4)$ & $39(75.6)$ & \\
\hline \multirow{2}{*}{ Tight outfit } & Yes & $29(45.3)$ & $24(54.7)$ & \multirow{2}{*}{0.01} \\
\hline & No & $14(29.8)$ & $33(70.2)$ & \\
\hline \multicolumn{5}{|c|}{ 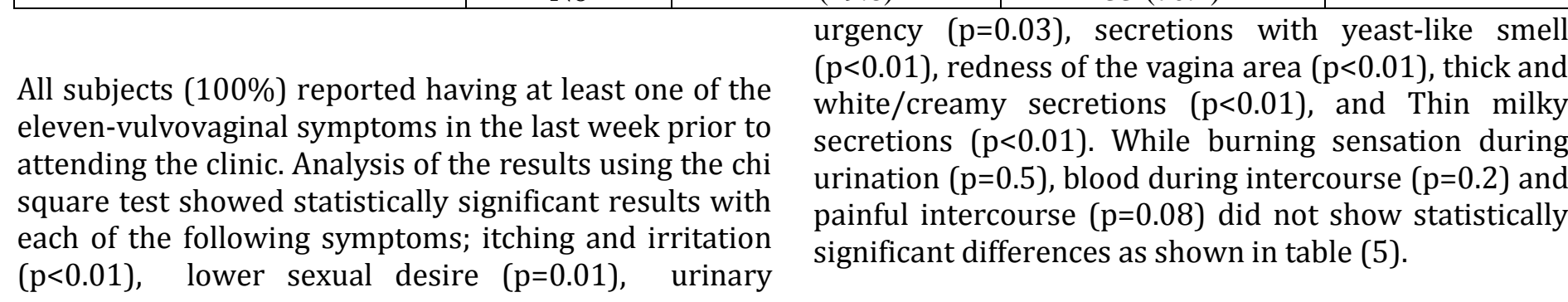 } \\
\hline
\end{tabular}

Table 5: The association between prevalence of vaginal candida Infection self-reported symptoms.

\begin{tabular}{|c|c|c|c|c|}
\hline \multicolumn{2}{|l|}{ Symptom } & $\begin{array}{c}\text { Positive } \\
\text { N }(\%)\end{array}$ & $\begin{array}{c}\text { Negative } \\
\mathbf{N}(\%)\end{array}$ & $p$-value \\
\hline \multirow{2}{*}{$\begin{array}{c}\text { Burning sensation during } \\
\text { urination }\end{array}$} & Yes & $26(40.6)$ & $38(59.4)$ & \multirow{2}{*}{0.5} \\
\hline & No & $17(47.2)$ & $19(52.8)$ & \\
\hline \multirow{2}{*}{ Itching and irritation } & Yes & $35(71.4)$ & $14(28.6)$ & \multirow{2}{*}{0.0} \\
\hline & No & $8(15.7)$ & $43(84.3)$ & \\
\hline \multirow{2}{*}{ Lower sexual desire } & Yes & $14(66.7)$ & $7(33.3)$ & \multirow{2}{*}{0.01} \\
\hline & No & $29(36.7)$ & $50(63.3)$ & \\
\hline \multirow{2}{*}{$\begin{array}{c}\text { Painful intercourse } \\
\text { (dyspareunia) }\end{array}$} & Yes & $10(62.5)$ & $6(37.5)$ & \multirow{2}{*}{0.08} \\
\hline & No & $33(39.3)$ & $51(60.7)$ & \\
\hline \multirow{2}{*}{ Blood during intercourse } & Yes & $1(100)$ & $0(0)$ & \multirow{2}{*}{0.2} \\
\hline & No & $42(42.4)$ & $57(57.6)$ & \\
\hline \multirow{2}{*}{ Urinary urgency } & Yes & $26(54.2)$ & $22(45.8)$ & \multirow{2}{*}{0.03} \\
\hline & No & $17(32.7)$ & $35(67.3)$ & \\
\hline \multirow{2}{*}{ Secretions smell Yeast like } & Yes & $23(92.0)$ & $2(8.0)$ & \multirow{2}{*}{0.00} \\
\hline & No & $20(26.7)$ & $55(73.3)$ & \\
\hline Thick and white/creamy & Yes & $27(84.4)$ & $5(15.6)$ & 0.00 \\
\hline
\end{tabular}




\begin{tabular}{|c|c|c|c|c|}
\hline \multicolumn{2}{|c|}{ Symptom } & $\begin{array}{c}\text { Positive } \\
\text { N (\%) }\end{array}$ & $\begin{array}{c}\text { Negative } \\
\mathbf{N}(\%)\end{array}$ & \multirow{2}{*}{$p$-value } \\
\hline secretions & No & $16(23.5)$ & $52(76.5)$ & \\
\hline \multirow{2}{*}{ Thin milky secretions } & Yes & $36(78.3)$ & $10(21.7)$ & \multirow{2}{*}{0.00} \\
\cline { 2 - 4 } Redness of the vagina area & No & $7(13)$ & $47(87)$ & \multirow{2}{*}{0.00} \\
\cline { 2 - 4 } & Yes & $27(75)$ & $9(25)$ & $48(75)$ \\
\hline
\end{tabular}

\section{Discussion}

This present study investigated the prevalence of vaginal candidiasis among pregnant women with symptoms of vaginal infection attending different gynecological clinic over the period of five months in a different area in Gaza city.

In the present study, the isolation rate of Candida spp. from pregnant women was $43 \%$. The highest rate was among $18-28$ age group with a prevalence of $46.4 \%$. These results are higher than those observed in previous reports on vaginal Candida spp. (33.8\%) in women in the age range of 20-29 years, followed by $(24.3 \%)$ those in the age range of 30-39 years, and the overall prevalence of VVC was 25\% (9). Other researchers reported lower results than ours including $17 \%$ obtained from Malaysia (10), $15-20 \%$ in Taiwan (11), $14 \%$ in Ibadan (12), 30\% in Nigeria (13), $37 \%$ in Turkey (14) and 38\% in Hyderabad (15). While our results were lower than (55.4\%) those obtained in Cameroon (16) and even very much lower than (92\%) in a report from Libya (17). Feyi (18) in Tanzania and Menza et al (19) in Kenya reported prevalence rates in agreement with our result; they reported that, prevalence of vaginal candidiasis among pregnant women were $42.9 \%, 42.7 \%$ respectively.

The high prevalence of vaginal candidiasis may due to many different reasons include; suppression of the immune system due to the pregnancy as it is among the contributing factors of vaginal candidiasis (20), extended and misuse of antibiotics which leads to the destruction of good and beneficial bacteria resulting to reduction of vaginal immunity could have also contributed to the increase of the prevalence of the infection $(21,22)$.

Virulent factors of Candida spp. like dimorphism, phenotypic switching, protease and phosphatase which enhance its attachment to human epithelium play an importance role in their high occurrence. High incidence rate also may due to increased physiological changes, estrogen and rich glycogen content of the vaginal mucosa thereby providing an adequate supply of utilizable sugar that favor Candida albicans growth during pregnancy (17).
In this study, only $5(11.6 \%)$ of Candida spp. was resistant to fluconazole, this is higher than studies conducted in United States and Brazil were all $C$. albicans vaginal isolates were susceptible to fluconazole (23), and zero resistance Malaysia (10). A study in Argentina (24) showed a slightly higher result (13.46\%).

Resistance of Candida isolates to nystatin was $9.3 \%$. This higher than previously reported in pregnant woman (only $0.61 \%$ ) in Peshawar (25). In our study miconazole and itraconazole was resistant in 5 and 4 $(11.6 \%, 9.3 \%)$ respectively of isolates. In an 8-years study, fluconazole resistance increased from $2.4 \%$ to $55.4 \%$ (2006-2012), but the rate dropped to $8.9 \%$ in 2013. Considering miconazole and itraconazole, resistance increased from $2.4 \%$ and $7.1 \%$ to $59.8 \%$ and 58.9\% (2006-2013), respectively (26).

Age, level of education, income, and residency as possible risk factors for vulvovaginitis were investigated in the present study. We did not find associations between some socio-demographic characteristics and the prevalence of vulvovaginal candidiasis. Among socio-demographic characteristics, age seems to be not an important factor in the overall occurrence of vulvovaginal candidiasis. Out of 43 patients with vulvovaginal candidiasis, 32 (46.4\%) patients were in their 18-28 of life. Our result was comparable with previous studies $(27,28)$.

The study of Janković et al. (29), showed that vulvovaginal candidiasis was statistically associated with continual wearing of tight underwear, a finding which is consistent with our result $(\mathrm{p}<0.01)$.

In the present study, the presenting complaints in $71.4 \%$ of positive patients reported itching and irritations, $75 \%$ Redness of the vagina area, $84.4 \%$ suffered from thick and white/creamy secretions, $92 \%$ Secretions smell Yeast like, $66.7 \%$ lower sexual desire, and $54.2 \%$ Urinary urgency. These is comparable to the prevalence rate obtained from Pakistan (25). This most likely owes to raised level of hormones during pregnancy, which is an energy source for Candida growth (6). pregnancy resulted significantly associated to asymptomatic infection (30). In other study, 39.5\% of pregnant women had symptoms of VV (31). 
Discharge was the most symptoms were noticed in pregnant followed by itching while odor and burning are present lowest percentages in all subjects (17). The frequency of vaginal candidiasis during pregnancy was found to be $38 \%$, in which $27 \%$ were symptomatic and $11 \%$ were asymptomatic group (15).

As this is the first study that investigated Candida among pregnant women, the authors were not able to compare the results of this study with local studies. Other studies should be conducted, to include larger sample and covers the entire Gaza strip. Gynecology clinics are recommended to perform culture and sensitivity to provide an appropriate antifungal. The concerned authorities should work closely to monitor the use of therapeutic antifungals to minimize drug resistance. Education of women on genital hygiene and regular screening for candidiasis in antenatal program is highly recommended.

\section{References:}

1. Adjapong GNY. Characterisation of Candida species: a case study in three teaching hospitals in Ghana. 2014.

2. Del-Cura González I, García-de-Blas González F, Cuesta TS, Fernández JM, Del-Alamo Rodríguez JM, Escriva Ferrairo RA, et al. Patient preferences and treatment safety for uncomplicated vulvovaginal candidiasis in primary health care. BMC public health. 2011;11(1):1-8

3. Anderson M, Karasz A, Friedland S. Are vaginal symptoms ever normal? A review of the literature. Medscape General Medicine. 2004;6(4).

4. Lisiak M, Kłyszejko C, Pierzchało T, Marcinkowski Z. Vaginal candidiasis: frequency of occurrence and risk factors. Ginekologia polska. 2000;71(9):964-70.

5. Barousse MM, Espinosa T, Dunlap K, Fidel PL. Vaginal epithelial cell anti-Candida albicans activity is associated with protection against symptomatic vaginal candidiasis. Infection and immunity. 2005;73(11):77657.

6. Ragunathan L, Poongothai G, Sinazer AR, Kannaiyan $\mathrm{K}$, Gurumurthy $\mathrm{H}$, Jaget $\mathrm{N}$, et al. Phenotypic characterization and antifungal susceptibility pattern to fluconazole in Candida species isolated from vulvovaginal candidiasis in a tertiary care hospital. Journal of clinical and diagnostic research: JCDR. 2014;8(5):DC01.

7. Norte R, Nordeste R, Centro-Oeste R, Sudeste R, Sul R. Ministério da Saúde Secretaria de Vigilância em Saúde Programa Nacional de DST e Aids.

8. CLSI. Performance Standards for Antifungal Susceptibility Testing of Yeasts. 1st ed. 950 West Valley Road, Suite 2500, Wayne, Pennsylvania 19087 USA: Clinical laboratory Science Institute.; 2017.

9. Limia OF, Lantero MI. Prevalence of Candida albicans and Trichomonas vaginalis in pregnant women in Havana City by an immunologic latex agglutination test. Medscape General Medicine. 2004;6(4).
10. Masri SN, Noor SM, Nor LAM, Osman M, Rahman MM. Candida isolates from pregnant women and their antifungal susceptibility in a Malaysian tertiary-care hospital. Pakistan journal of medical sciences. 2015;31(3):658.

11. Tseng Y-H, Lee W-T, Kuo T-C. In-Vitro susceptibility of fluconazole and amphotericin B against Candida isolates from women with Vaginal Candidiasis in Taiwan. Journal of Food and Drug Analysis. 2005;13(1).

12. Anorlu R, Imosemi D, Odunukwe $\mathrm{N}$, Abudu $\mathrm{O}$, Otuonye M. Prevalence of HIV among women with vaginal discharge in a gynecological clinic. Journal of the National Medical Association. 2004;96(3):367.

13. Okonkwo N, Umeanaeto P. Prevalence of vaginal candidiasis among pregnant women in Nnewi town of Anambra State, Nigeria. African research review. 2010;4(4).

14. Guzel AB, Ilkit M, Burgut R, Urunsak IF, Ozgunen FT. An evaluation of risk factors in pregnant women with Candida vaginitis and the diagnostic value of simultaneous vaginal and rectal sampling. Mycopathologia. 2011;172(1):25-36.

15. Parveen N, Munir AA, Din I, Majeed R. Frequency of vaginal candidiasis in pregnant women attending routine antenatal clinic. Journal of the College of Physicians and Surgeons--Pakistan: JCPSP. 2008;18(3):154-7.

16. Toua V, Djaouda M, Gaké B, Menye DE, Christie E, Tambe E, et al. Prevalence of Vulvovaginal Candidiasis amongst pregnant women in Maroua (Cameroon) and the sensitivity of Candida albicans to extracts of six locally used antifungal plants. Int Res J Microbiol. 2013;4(3):89-97.

17. Altayyar IA, Alsanosi AS, Osman NA. Prevalence of vaginal candidiasis among pregnant women attending different gynecological clinic at South Libya. European Journal of Experimental Biology. 2016;6(3):25-9.

18. Menza N, Wanyoike W, Muturi M. Prevalence of vaginal candidiasis and determination of the occurrence of Candida species in pregnant women attending the antenatal clinic of Thika District Hospital, Kenya. 2013.

19. Mumuney K, Abalaka M. Comparative Study of Vaginal Candidiasis in Pregnant and Non-Pregnant Women Attending Ibrahim Badamasi Babangida Specialist Hospital and General Hospital, Minna Niger State, Nigeria. Journal of Advances in Microbiology. 2019:1-7.

20. Isibor J, Samuel S, Nwaham C, Amanre I, Igbinovia O, Akhile A. Prevalence of bacterial and Candida albicans infection amongst women attending Irrua Specialist Teaching Hospital, Irrua, Nigeria. African Journal of Microbiology Research. 2011;5(20):3126-30.

21. Bander KI, Hamad TA. Prevalence of Vaginal Candidiasis among women and Diagnosis of Candida species from vaginal infection in Kirkuk city. Tikrit Journal of Pure Science. 2018;20(4):5-15.

22. Limia F. 0, Lantero MI, Betancourt A, de Armas E, Villoch A. Prevalence of Candida al-bicans and Trichomonas vaginalis in pregnant women in Havana city by an immunologic latex agglutination test. MedGenMed. 2004;6(4):50. 
23. Sobel JD, Wiesenfeld HC, Martens M, Danna $P$, Hooton TM, Rompalo A, et al. Maintenance fluconazole therapy for recurrent vulvovaginal candidiasis. New England Journal of Medicine. 2004;351(9):876-83.

24. Saporiti A, Gomez D, Levalle S, Galeano M, Davel G, Vivot W, et al. Vaginal candidiasis: etiology and sensitivity profile to antifungal agents in clinical use. Revista Argentina de microbiologia. 2001;33(4):217-22.

25. Khan M, Ahmed J, Gul A, Ikram A, Lalani FK. Antifungal susceptibility testing of vulvovaginal Candida species among women attending antenatal clinic in tertiary care hospitals of Peshawar. Infection and drug resistance. 2018;11:447.

26. Wang F-J, Zhang D, Liu Z-H, Wu W-X, Bai H-H, Dong $\mathrm{H}-\mathrm{Y}$. Species distribution and in vitro antifungal susceptibility of vulvovaginal Candida isolates in China. Chinese medical journal. 2016;129(10):1161.

27. Sobel JD, Faro S, Force RW, Foxman B, Ledger WJ, Nyirjesy PR, et al. Vulvovaginal candidiasis: epidemiologic, diagnostic, and therapeutic considerations. American journal of obstetrics and gynecology. 1998;178(2):203-11.

28. Bitew A, Abebaw Y. Vulvovaginal candidiasis: species distribution of Candida and their antifungal susceptibility pattern. BMC women's health. 2018;18(1):94.

29. Bohm-Starke N. NVA Research Update E-Newsletter. Acta Obstet Gynecol Scand. 2010;89(12):1504-10.

30. Leli C, Mencacci A, Meucci M, Bietolini C, Vitali M, Farinelli $S$, et al. Association of pregnancy and Candida vaginal colonization in women with or without symptoms of vulvovaginitis. Minerva ginecologica. 2013;65(3):303-9.

31. Mucci MJ, Cuestas ML, Cervetto MM, Landaburu MF, Mujica MT. A prospective observational study of vulvovagintis in pregnant women in Argentina, with special reference to candidiasis. Mycoses. 2016;59(7):429-35. 